(C)2003 IEEE. Personal use of this material is permitted. However, permission to reprint/republish this material for advertising or promotional purposes or for creating new collective works for resale or redistribution to servers or lists, or to reuse any copyrighted component of this work in other works must be obtained from the IEEE. 


\title{
Magnetic Properties of Sm-Fe-N Thick Film Magnets Prepared by the Aerosol Deposition Method
}

\author{
S. Sugimoto, T. Maeda, R. Kobayashi, J. Akedo, M. Lebedev, and K. Inomata
}

\begin{abstract}
This paper describes magnetic properties of Sm-Fe-N films prepared by an aerosol deposition method. The films with thickness of 3-45 $\mu \mathrm{m}$ were obtained by the deposition within $10 \mathrm{~min}$ and the deposition rate was estimated as approximately 2-10 $\mu \mathrm{m} / \mathrm{min}$. The $\mathrm{Sm}-\mathrm{Fe}-\mathrm{N}$ films showed relatively high micro Vickers hardness in the range from 500 to 700 . The remanence of the $\mathrm{Sm}-\mathrm{Fe}-\mathrm{N}$ films was approximately $0.4 \mathrm{~T}$, which was lower than that of initial host powders. However, almost of all samples showed higher coercivities around $1.8 \mathrm{~T}$.
\end{abstract}

Index Terms-Aerosol deposition method (ADM), coercivity, high deposition rate, $\mathrm{Sm}-\mathrm{Fe}-\mathrm{N}$ film.

\section{INTRODUCTION}

$\mathbf{R}$ ARE-EARTH magnets with thickness less than $300 \mu \mathrm{m}$ can reduce the size of motors and accelerate the development of electromobile devices. Although a reduction in thickness of bulk rare earth magnets mechanically is a simple method to realize the size reduction, the mechanical method deteriorates the magnetic properties. On the other hand, a sputtering method is convenient to obtain film magnets [1]-[3], however, it is difficult to obtain a high-speed deposition rate. Very recently, many researchers have applied a plasma laser deposition (PLD) in preparing rare earth film magnets because of high deposition rate [4]-[6]. However, deposition rate has not been sufficient for manufacturing film magnets for the use in electro-mobile devices.

The aerosol deposition method (ADM) reported as one of the fabrication processes for fine ceramics films such as PZT and $\mathrm{Al}_{2} \mathrm{O}_{3}$, is expected to achieve a high deposition rate and high film density [7], [8]. The deposition rate of this method was reported as $5-50 \mu \mathrm{m} / \mathrm{min}$, which is attractive for a deposition technique for thick films with thickness of 1-100 $\mu \mathrm{m}$. The principle of the ADM is based on shock loading densification due to the impact of ultra fine particles, which are accelerated by a carrier gas. It is considered that during impacts of the ultra-fine particles (UFP) flow with the substrate, a part of UFP's kinetic energy is converted to bonding energy between the substrate and the UFPs, and between the UFPs themselves. Judging from the

Manuscript received December 26, 2002. This work was supported in part by NEDO Project of Nano Structure Forming for Ceramics Integration Project in Nano Technology Program in Japan.

S. Sugimoto, T. Maeda, R. Kobayashi, and K. Inomata are with the Department of Materials Science, Graduate School of Engineering, Tohoku University, Sendai 980-8579, Japan (e-mail: sugimots@ material.tohoku.ac.jp).

J. Akedo and M. Lebedev are with the National Institute of Advanced Industrial Science and Technology (AIST), Ibaraki 305-8564, Japan (e-mail: akedo-j@aist.go.jp).

Digital Object Identifier 10.1109/TMAG.2003.816715

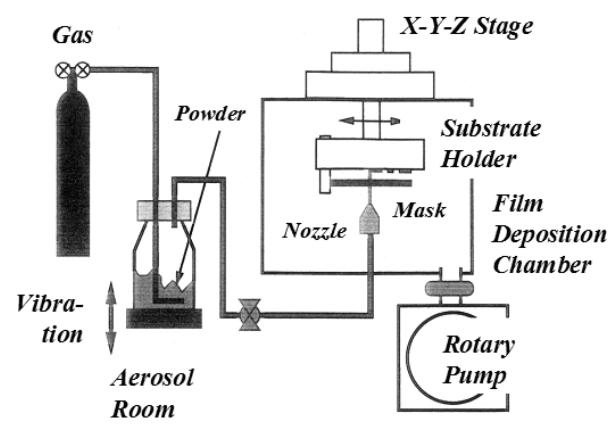

Fig. 1. The schematic illustration of the aerosol deposition method.

features of the ADM, this process has a possible candidate for the fabrication methods of rare-earth thick film magnets. Therefore, the purpose of this investigation was to apply the ADM to the fabrication of rare earth film magnets and to investigate their magnetic properties.

\section{EXPERIMENTAL PROCEDURE}

The powder for the ADM was the $\mathrm{Sm}_{2} \mathrm{Fe}_{17} \mathrm{~N}_{\mathrm{x}}$ powder prepared by the Sumitomo Metal Mining Co. Ltd. The average particle size of host powders was approximately $3 \mu \mathrm{m}$. The schematic illustration of the ADM apparatus is shown in Fig. 1. The $\mathrm{Sm}_{2} \mathrm{Fe}_{17} \mathrm{~N}_{\mathrm{x}}$ fine powders formed an aerosol flow by mixing with a carrier gas in the aerosol chamber. The aerosol flow was transported through a tube to nozzle. This flow was accelerated and ejected from the nozzle with an orifice of $10 \times 0.4 \mathrm{~mm}^{2}$ into the deposition chamber, which was evacuated by a rotary pump with mechanical buster. Helium gas was used as a carrier gas. To control the fine powders velocity, the gas consumption (gas flow rate: gfr) was varied from 1 to $10 \mathrm{l} / \mathrm{min}$. The pressures in the deposition and aerosol chamber were 20-100 $\mathrm{Pa}$ and 8-60 $\mathrm{kPa}$, respectively. The substrates used in this investigation were glass and $\mathrm{SiO}_{2}$ plates. They were placed at a distance of 1-20 $\mathrm{mm}$ from the nozzle and were maintained at room temperature. The $\mathrm{Sm}_{2} \mathrm{Fe}_{17} \mathrm{~N}_{\mathrm{x}}$ fine powders were bombarded on to the substrates and formed the films.

The thickness of films was measured by a Dektak profilometer and an optical microscope. The hardness of obtained films was evaluated using a micro Vickers hardness tester. The magnetic properties were measured by a vibrating sample magnetometer (VSM) after applying a pulsed field around 4 $\mathrm{T}$, and the microstructures were observed using X-ray diffraction (XRD), an optical microscope and scanning electron microscopy (SEM) techniques. 


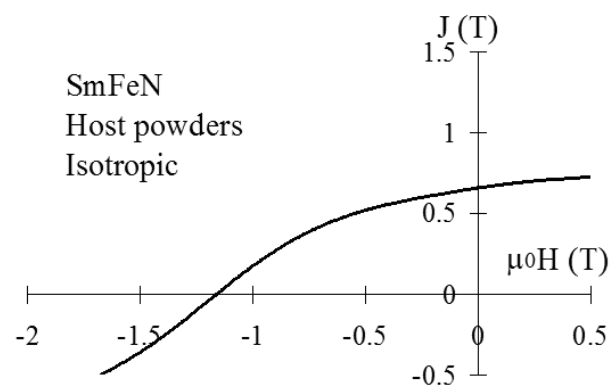

Fig. 2. The demagnetization curve of $\mathrm{Sm}-\mathrm{Fe}-\mathrm{N}$ host powders before the ADM.

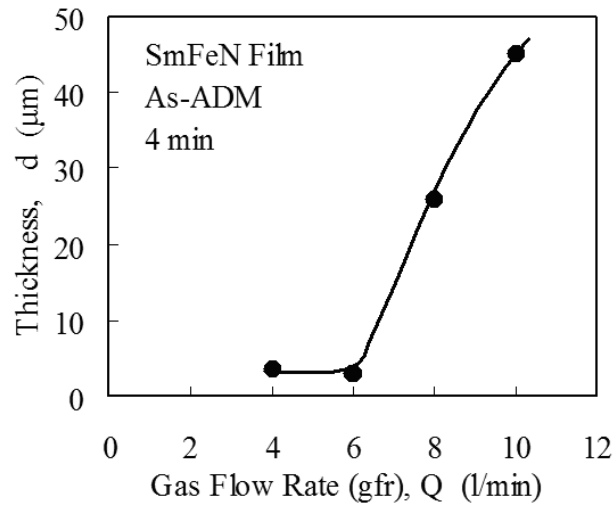

Fig. 3. Variation of $\mathrm{Sm}-\mathrm{Fe}-\mathrm{N}$ film thickness versus gas flow rate (gfr) during the $\mathrm{ADM}$ for $4 \mathrm{~min}$.

\section{RESULTS}

First of all, magnetic properties of the precursor $\mathrm{Sm}-\mathrm{Fe}-\mathrm{N}$ powders were measured by VSM without alignment of powders. The result is shown in Fig. 2. The demagnetization curve exhibited magnetically an isotropic feature, and the powders showed remanence $(\mathrm{Br})$ of $0.66 \mathrm{~T}$ and coercivity $\left(\mu_{0} \mathrm{H}_{\mathrm{CJ}}\right)$ of $1.16 \mathrm{~T}$, respectively. (The reported X-ray density of the $\mathrm{Sm}_{2} \mathrm{Fe}_{17} \mathrm{~N}_{3}$ compound $\left(7.67 \mathrm{~kg} / \mathrm{mm}^{3}\right)$ was used as the density of $\mathrm{Sm}-\mathrm{Fe}-\mathrm{N}$ precursor powders for the calculation of magnetization.) Using these powders, the $\mathrm{Sm}-\mathrm{Fe}-\mathrm{N}$ thick films were prepared by the ADM. Unfortunately, the surface of deposited $\mathrm{Sm}-\mathrm{Fe}-\mathrm{N}$ films was not so flat and the thickness of each film had a relatively wide range. Therefore, the thickness of films was reported using their average values. Fig. 3 shows the variation of $\mathrm{Sm}-\mathrm{Fe}-\mathrm{N}$ film thickness deposited by the ADM for 4 min versus gas flow rate (gfr) during the ADM. Sm-Fe-N films were not obtained in the condition of $\mathrm{gfr}=2 \mathrm{l} / \mathrm{min}$. However, the thickness of the films increased with increasing gfr, resulting in a maximum thickness of $45 \mu \mathrm{m}$ with gfr $=10 \mathrm{l} / \mathrm{min}$. Fig. 4 also shows thickness of $\mathrm{Sm}-\mathrm{Fe}-\mathrm{N}$ films deposited for 2-8 min in the condition of gfr $=4$ or $81 / \mathrm{min}$. The film thickness reached 13 or $41 \mu \mathrm{m}$ with gfr $=4$ or $8 \mathrm{l} / \mathrm{min}$ for $8 \mathrm{~min}$, respectively. From these results, shown in Figs. 3 and 4, the deposition rate of the ADM was varied in the range of $2-10 \mu \mathrm{m} / \mathrm{min}$ and it can be said that the ADM has a remarkably higher deposition rate for the fabrication of $\mathrm{Sm}-\mathrm{Fe}-\mathrm{N}$ films than conventional sputtering methods. Fig. 5 shows micro Vickers hardness of the $\mathrm{Sm}-\mathrm{Fe}-\mathrm{N}$ films de-

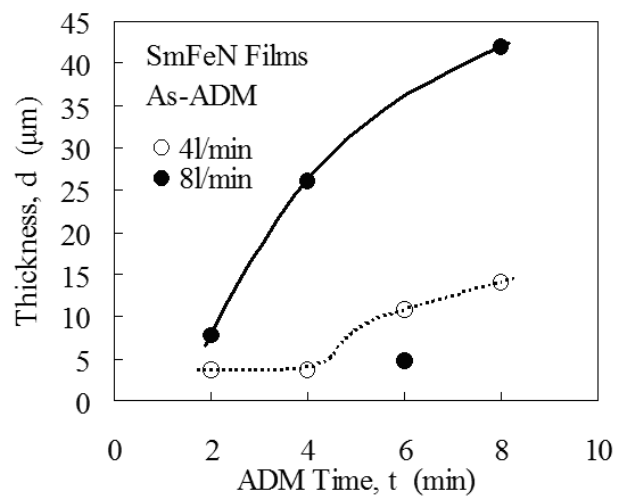

Fig. 4. Thickness of the $\mathrm{Sm}-\mathrm{Fe}-\mathrm{N}$ films deposited by the ADM in the conditions of gfr $=4$ or $81 / \mathrm{min}$ for 2-8 $\mathrm{min}$.

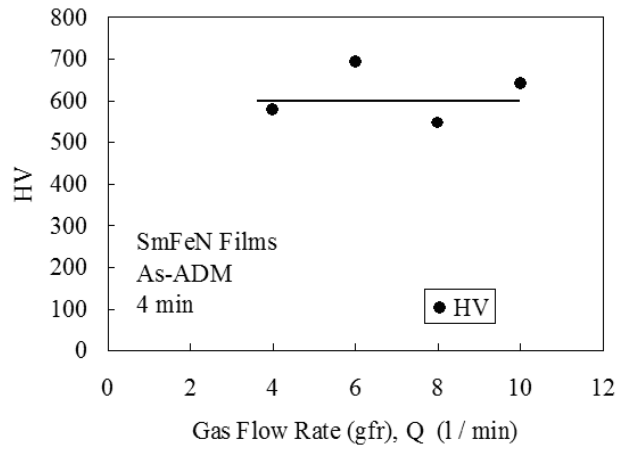

Fig. 5. Variation of Vickers hardness of $\mathrm{Sm}-\mathrm{Fe}-\mathrm{N}$ films versus gas flow rate (gfr) during the ADM.

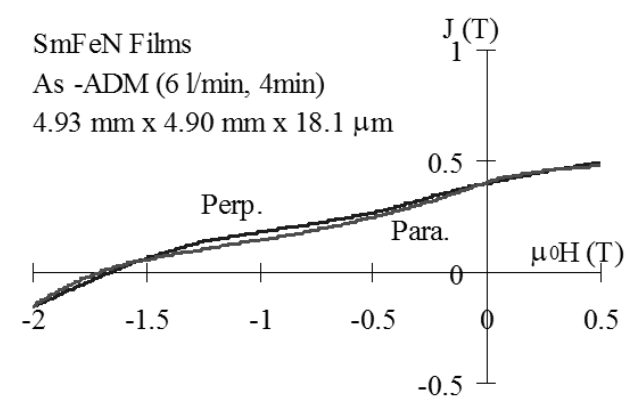

Fig. 6. Demagnetization curves of $\mathrm{Sm}-\mathrm{Fe}-\mathrm{N}$ films deposited by the ADM in the conditions of $\mathrm{gfr}=6 \mathrm{l} / \mathrm{min}$ for $4 \mathrm{~min}$.

posited with gfr $=2-10 \mathrm{l} / \mathrm{min}$ for $4 \mathrm{~min}$. They showed the relative high values in the range from 500 to 700 .

Fig. 6 shows the demagnetization curves of $\mathrm{Sm}-\mathrm{Fe}-\mathrm{N}$ films deposited by the ADM in the condition of gfr $=61 / \mathrm{min}$ for 4 min, which were measured in directions parallel (para) or perpendicular (perp) to the film plane. An inflection observed in each demagnetization curve suggested that the film consisted of two phases. (One was with high coercivity and low magnetization and another was with high magnetization and low coercivity.) The film exhibited the remanence of $0.43 \mathrm{~T}$, which was calculated using the average film thickness of $18 \mu \mathrm{m}$ and the remanence was remarkably lower than that of precursor powders shown in Fig. 2. This decrease was considered to be due to 


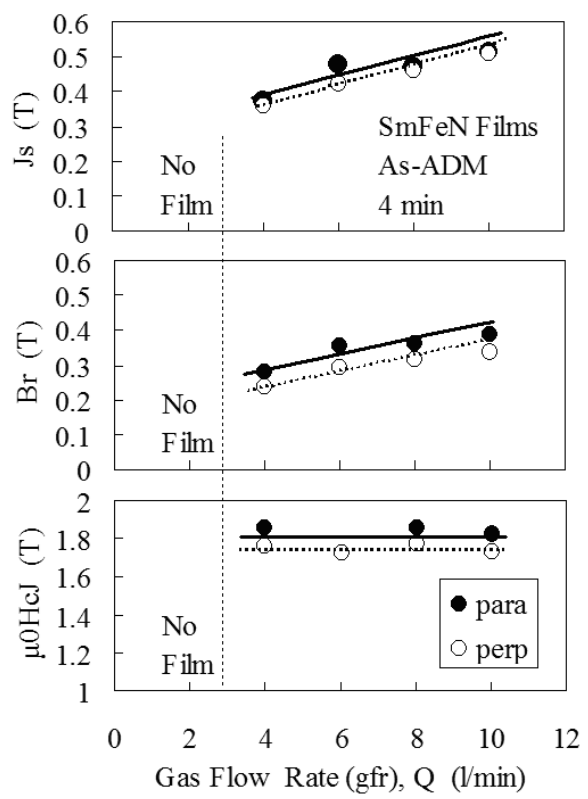

Fig. 7. Magnetic properties of $\mathrm{Sm}-\mathrm{Fe}-\mathrm{N}$ films prepared by the ADM in the conditions of $\mathrm{gfr}=2-10 \mathrm{l} / \mathrm{min}$ for $4 \mathrm{~min}$.

low film density or oxidation during the ADM, as the vacuum level of the ADM was quite low in comparison with that of conventional sputtering techniques. However, the coerecivity of the film was $1.70 \mathrm{~T}$, which was higher than that of host powders. This high coercivity was obtained in as-deposition state without annealing and this feature is one of advantages of the ADM.

Fig. 7 shows magnetic properties of the $\mathrm{Sm}-\mathrm{Fe}-\mathrm{N}$ films deposited by the ADM in the conditions of gfr $=2-10 \mathrm{l} / \mathrm{min}$ for $4 \mathrm{~min}$. The coercivities were almost the same in all samples and the values were around 1.8 T. Since the remanence and saturation magnetization (Js) were lower than those of host powders, they showed a tendency to increase with increasing gfr. This increase was considered to be due to the increase in film density or the decrease in the ratio of oxidized region in films during increase in film thickness caused by increasing gfr, as shown in Fig. 3.

To our knowledge, this paper may be the first to report magnetic properties of rare earth magnet films prepared by the ADM. In order to develop magnetic properties of the rare earth magnet films prepared by the ADM, many improvements such as increase in remanence, are strongly needed. However, it can be considered that the ADM has a possibility to become a candidate for the fabrication process of rare earth magnet films because of its high deposition rate.

\section{ACKNOWLEDGMENT}

The authors would like to thank to T. Ishikawa, Sumitomo Metal Mining Co. Ltd., Central Research Laboratory, Ichikawa, Japan, for providing $\mathrm{Sm}-\mathrm{Fe}-\mathrm{N}$ powders.

\section{REFERENCES}

[1] F. J. Cadieu, T. D. Cheung, and L. Wickramasekara, "Magnetic properties of sputtered Nd-Fe-B films," J. Magn. Magn. Mater., vol. 54-57, pp. 535-536, 1986.

[2] S. Yamashita, J. Yamasaki, M. Ikeda, and N. Iwabuchi, "Anisotropic Nd-Fe-B thin-film magnets for milli-size motor," J. Appl. Phys., vol. 70, pp. 6627-6629, 1991.

[3] R. Rani, H. Hegde, A. Navarathna, and F. J. Cadieu, "High coercivity $\mathrm{Sm}_{2} \mathrm{Fe}_{17} \mathrm{~N}_{\mathrm{x}}$ and related phases in sputtered film samples," J. Appl. Phys., vol. 73, pp. 6023-6025, 1993.

[4] M. Nakano, S. Tsutsumi, and H. Fukunaga, "Magnetic properties of $\mathrm{Nd}-\mathrm{Fe}-\mathrm{B}$ thick-film magnets prepared by laser ablation technique," IEEE Trans. Magn., vol. 38, pp. 2913-2915, 2002

[5] F. J. Gadieu, "Rare earth transition metal film permanent magnets," in Proc. 17th Int. Workshop Rare Earth Magnets and Their Applications, G. C. Hadjipanayis and M. J. Bonder, Eds., 2002, pp. 416-427.

[6] D. J. Sellmyer, J. Zhou, Y. Liu, and R. Skomski, "Magnetism of sputtered Sm-Co-based thin films," in Proc. 17th Int. Workshop Rare Earth Magnets and Their Applications, G. C. Hadjipanayis and M. J. Bonder, Eds., 2002, pp. 428-437.

[7] C. Hayashi, S. Kashu, M. Oda, and F. Naruse, "The use of nanoparticles as coatings," Mater. Sci. Eng. A, vol. 163, pp. 157-161, 1993.

[8] J. Akedo and M. Lebedev, "Influence of carrier gas conditions on electrical and optical properties of $\mathrm{Pb}(\mathrm{Zr}, \mathrm{Ti}) \mathrm{O} 3$ thin films prepared by aerosol deposition method," Jpn. J. Appl. Phys., vol. 40, pp. 5528-5532, 2001 